\title{
UN CONVENIO INTERNACIONAL PERDIDO Y HALLADO EN LAS ISLAS BALEARES: REFLEXIONES SOBRE EL CONTROL DE OFICIO DE LA COMPETENCIA JUDICIAL INTERNACIONAL Y LAS FUENTES DEL DERECHO INTERNACIONAL PRIVADO ESPAÑOL
}

\author{
A INTERNATIONAL CONVENTION LOST AND FOUND IN THE \\ BALEARIC ISLANDS: REFLECTIONS ON THE EXAMINATION \\ AS TO INTERNATIONAL JURISDICTION AND THE SOURCES \\ OF SPANISH PRIVATE INTERNATIONAL LAW
}

\author{
Alfonso-Luis Calvo Caravaca \\ Catedrático de Derecho internacional privado \\ Universidad Carlos III de Madrid \\ Vocal Permanente de la Comisión General de Codificación \\ JaVier Carrascosa GonzÁlez \\ Catedrático de Derecho Internacional Privado \\ Universidad de Murcia
}

Recibido: 21.12.2016 / Aceptado: 11.01.2017

DOI: https://doi.org/10.20318/cdt.2017.3627

\begin{abstract}
Resumen: El presente trabajo examina la importancia de la correcta selección, por jueces y litigantes, de las fuentes normativas que regulan la competencia internacional de los tribunales españoles. En dicho contexto, se estudia también el principio constitucional con arreglo al cual los tribunales españoles sólo pueden decidir sobre el fondo de un litigio internacional si disponen de competencia internacional al efecto, con independencia de la actitud de las partes.
\end{abstract}

Palabras clave: competencia internacional, jurisdicción, fuentes del Derecho, control de la competencia internacional, declinatoria internacional.

Abstract: The present article examines the importance of the correct selection, by judges and parties, of the sources of law that govern the international jurisdiction of the Spanish courts. In that scenario, it also examines the constitutional principle under which Spanish courts can only decide on the merits of international disputes if international jurisdiction is asserted, irrespective of parties' behaviour.

Keywords: international jurisdiction, sources of law, examination as to international jurisdiction, contesting the jurisdiction.

Sumario: I. El caso litigioso y las resoluciones judiciales. II. Las motivaciones de la Audiencia Provincial de las Islas Baleares para declarar la falta de competencia de los tribunales españoles. 1. Vigencia y aplicación preferente del Convenio hispano-griego de 1919 sobre el art. 22 LOPJ. 2. Competencia judicial internacional y litigios sucesorios en el Convenio hispano-griego de 1919. A) Foros de competencia judicial internacional recogidos en el Convenio hispano-griego de 6 marzo 1919. a) 
Aspectos generales. b) Competencia judicial internacional y sucesión mortis causa en relación con los bienes muebles: foro de la última nacionalidad del causante. c) Competencia judicial internacional y sucesión mortis causa en relación con los bienes inmuebles: foro del lugar de situación de los bienes inmuebles. B) Declaración de incompetencia de los tribunales españoles. a) Principio general: no hay proceso sin competencia internacional. b) La declinatoria internacional. c) La abstención de oficio por falta de competencia internacional. III. Reflexiones finales.

\section{El caso litigioso y las resoluciones judiciales}

1. La SAP Islas Baleares 4 mayo 2016 [sucesión de nacional griego] es una resolución judicial verdaderamente peculiar ${ }^{1}$. Peculiar por su objeto, peculiar por la solución que alcanza y peculiar por las reflexiones a las que invita al lector, sobre todo si es curioso. Expuesto de manera sumaria, el caso fue el siguiente. Un sujeto, titular de un ingente patrimonio y con diversas residencias en Italia, España, Rumanía y Grecia, fallece en este último país. El causante había nacido en Rumanía y ostentaba la nacionalidad rumana de origen. Adquirió en 1978 la nacionalidad española y en 2000 la nacionalidad griega. Un presunto hijo no matrimonial de dicho causante interpuso, ante jueces de Palma de Mallorca, una demanda contra la viuda del causante y contra los hijos de ambos, todos ellos menores de edad. Ejercitó una acción de declaración de nulidad de la institución de herederos testamentarios, y subsidiariamente, una acción de reclamación de legítima respecto del testamento otorgado por el causante. El causante, en efecto, había otorgado testamento ológrafo en la ciudad de Milán, testamento que fue protocolizado en Grecia, en el que había preterido a su presunto hijo no matrimonial. Éste no fue nombrado a ningún efecto en tal testamento. El causante siempre negó su paternidad en relación al mismo. En virtud de dicho testamento ológrafo, el causante atribuyó a sus hijos matrimoniales y a la esposa que lo fuera del causante, partes equivalentes de su herencia. El presunto hijo no matrimonial del causante, que ostentaba la nacionalidad alemana, había obtenido de tribunal alemán una sentencia firme en la que se acreditaba su condición de "hijo del causante". La sentencia alemana se dictó con la oposición del causante, fue apelada y finalmente confirmada por los tribunales alemanes. Esta sentencia alemana fue reconocida en Grecia y ello comportó la modificación del Registro Civil griego. Dicha sentencia nunca fue reconocida en España.

2. La primera línea de defensa de la parte demandada fue la impugnación de la competencia internacional de los jueces españoles mediante la oportuna "declinatoria internacional". Ésta se interpuso en tiempo y forma. En virtud de Auto dictado por un Juzgado de Primera Instancia de Palma de Mallorca en 2009 se estimó esta declinatoria. El Juzgado consideró que el domicilio del causante se hallaba en Atenas (Grecia) y que por tanto, los tribunales españoles carecían de competencia internacional para juzgar el caso en virtud del art. 22 LOPJ en su versión entonces vigente, anterior a la actual ${ }^{2}$. Debe observarse que el Juzgado decidió sobre la declinatoria mediante la aplicación del art. 22.3 LOPJ y que estimó que los foros recogidos en dicho precepto no otorgaban competencia judicial internacional a los tribunales españoles, que debían, por consiguiente, declararse internacionalmente incompetentes.

3. El contraataque de la parte demandante se materializó en el inevitable recurso de apelación contra el auto que estimaba la declinatoria de competencia internacional. La Sala acordó estimar el recurso de apelación contra el auto dictado por el Juzgado de Primera Instancia de Palma de Mallorca. La Sala consideró, en efecto, que los tribunales españoles disponían de competencia internacional. A criterio de la Sala, el último domicilio del causante estuvo en Palma de Mallorca. En consecuencia, y

1 Sentencia de la Audiencia Provincial de las Islas Baleares de 4 mayo 2016, ECLI:ES:APIB:2016:734 / Id Cendoj: 07040370032016100126. El texto íntegro de esta sentencia puede consultarse en http://www.poderjudicial.es/search/doActi on?action $=$ contentpdf\&databasematch $=A N \&$ reference $=7718740 \&$ links $=$ hispano $\% 20$ griego\&optimize $=20160624 \&$ publicinte rface=true. $\mathrm{Vid}$. un excelente comentario sobre esta sentencia a cargo de S. Álvarez GonZÁlez, "Nota a la sentencia AP Islas Baleares 4 mayo 2016", Anuario Español de Derecho internacional privado, 2016, pp. 1171-1172.

2 La Ley Orgánica del Poder Judicial fue publicada en el BOE núm.157 de 2 de julio de 1985, con corrección de errores en BOE núm.264 de 4 noviembre de 1985 y ha sido reformada y modificada en innumerables ocasiones. La redacción hoy vigente obedece a la Ley Orgánica 7/2015, de 21 de julio, por la que se modifica la Ley Orgánica 6/1985, de 1 de julio, del Poder Judicial (BOE núm. 174 de 22 de julio 2015). 
con arreglo al art. 22.3 LOPJ en su versión entonces vigente, la Sala sostuvo que los tribunales españoles eran competentes para conocer del litigio planteado ante los jueces de Palma de Mallorca en torno a la sucesión del causante. Por ello, la Sala revocó el auto referido, desestimó la declinatoria por falta de competencia internacional interpuesta por la parte demandada y acordó, ya en el año 2010, la continuación del procedimiento en el Juzgado de Primera Instancia competente de Palma de Mallorca.

4. El Juzgado de primera instancia entró, pues, obligado por la decisión de la Sala sobre la apelación de la declinatoria internacional, en el fondo del asunto y dictó sentencia el 10 abril 2015. En dicha sentencia el Juzgado estimó parcialmente la demanda formulada por el actor alemán y declaró el derecho de éste a percibir parte de la herencia del causante en cuestión en concepto de legitimario o heredero forzoso. Como es natural, ello comportaba la reducción del testamento ológrafo, esto es, la reducción de las instituciones de herederos en la medida necesaria a fin de satisfacer la cuota legitimaria del demandante, presunto hijo no matrimonial del causante.

5. La anterior sentencia fue apelada y la Audiencia Provincial de Palma de Mallorca dictó sentencia el 4 mayo 2016. En virtud de tal sentencia, la Audiencia revoco la sentencia de primera instancia y declaró la falta de competencia internacional de los tribunales españoles para conocer del fondo asunto, que queda, así, sin solución sobre el fondo.

\section{Las motivaciones de la Audiencia Provincial de Palma de Mallorca para declarar la falta de competencia de los tribunales españoles}

\section{Vigencia y aplicación preferente del Convenio hispano-griego de 1919 sobre el art. 22 LOPJ}

6. La cuestión clave para declarar la falta de competencia de los tribunales españoles para conocer de este pleito sucesorio fue, sin duda, la precisión de la normativa de Derecho internacional privado aplicable a la cuestión. En efecto, en primera instancia, el juzgado decidió que los tribunales españoles carecían de competencia internacional en relación con este litigio mediante la aplicación del art. 22.3 LOPJ. Sin embargo, en segunda instancia, la Audiencia no tuvo en cuenta el citado art. 22.3 LOPJ, sino que aplicó el "Convenio entre España y Grecia, celebrado el 6 marzo 1919, fijando reglas que se han de aplicar a las sucesiones de los españoles y de los griegos fallecidos en Grecia y en España, respectivamente"3.

7. Es evidente que something happened on the way to Heaven: algo ocurrió en el camino hacia el Cielo. Algo ocurrió entre la primera instancia y la segunda. En efecto, el Juzgado de primera instancia, en su sentencia sobre el caso, no había advertido la existencia y aplicación a este supuesto del referido Convenio internacional bilateral entre España y Grecia. Tampoco las partes se habían percatado de la existencia y aplicación a este concreto supuesto de este Convenio internacional. Sin embargo, en la segunda instancia, el escenario normativo en el que se movieron partes y tribunal cambió radicalmente. La explicación a este cambio de panorama legal es sencilla. La importancia cuantitativa y cualitativa del litigio así como la complejidad del mismo hizo que ambas partes buscaran asesoramiento especializado en diversos expertos de Derecho internacional privado en ese camino entre la sentencia de primera instancia y la apelación. El resultado de dicho asesoramiento fue que la parte demandada, ahora apelante, procedió al descubrimiento de un Convenio internacional firmado y ratificado por España, publicado en

\footnotetext{
3 El texto oficial de este Convenio puede verse en la Gaceta de Madrid núm. 338 de 3 diciembre 1920. Dicho texto original y oficial puede consultarse en: https://www.boe.es/datos/pdfs/BOE//1920/338/A00952-00955.pdf. Este Convenio es ya inaplicable para España y también para Grecia tras la entrada en vigor y plena aplicabilidad del Reglamento (UE) 650/2012 del Parlamento Europeo y del Consejo de 4 de julio de 2012 relativo a la competencia, la ley aplicable, el reconocimiento y la ejecución de las resoluciones, a la aceptación y la ejecución de los documentos públicos en materia de sucesiones mortis causa y a la creación de un certificado sucesorio europeo (DOUE L 201 de 27 julio 2012). Sobre las cuestiones temporales relacionadas con este Reglamento, vid., ad ex., P. Franzina, "Articles 83 \& 84”, en A.-L. Calvo Caravaca/A. Davi/H.-P. Mansel (Eds.), The EU Succession Regulation: A Commentary, Cambridge, Cambridge University Press, 2016, pp. 852-866.
} 
el diario legislativo oficial español de la época, -la Gaceta de Madrid-, y del que no constaban datos de su aplicación en España pero sí de su plena vigencia en el año 2009, fecha de inicio del litigio ante los tribunales baleares.

8. Es claro que algunos de los asesores legales de la parte demandada y posteriormente apelante, especializado en Derecho internacional privado, aconsejó redactar el recuso de apelación fundado en la falta de competencia internacional de los tribunales españoles pero sobre una base jurídica diferente hasta la ahora empleada. Había que fundar el recurso de apelación en el referido Convenio bilateral hispano-griego de 1919. Ya no se trataba de articular y proponer una "declinatoria internacional". En efecto, el momento procesal para proponer tal incidente había ya precluido en la primera instancia. Se trataba de proponer como fundamento jurídico de fondo en el recurso de apelación contra la sentencia dictada en primera instancia, la falta de competencia internacional de los tribunales españoles. Y dicho argumento había que fundarlo sobre la base jurídica, no considerada durante la primera instancia ni por las partes ni por el juzgado, del ya tantas veces nombrado Convenio bilateral hispano-griego.

9. El planteamiento del recurrente en apelación triunfó: la Audiencia provincial de las Islas Baleares, con sede en Palma de Mallorca, aplicó dicho Convenio internacional y declaró la falta de competencia internacional de los tribunales españoles para conocer del litigio en su sentencia de 4 mayo 2016.

10. El criterio seguido por la Audiencia de Palma en relación con la determinación de la normativa de Derecho internacional privado aplicable al litigio es acertado y ello es por varios motivos.

11. En primer lugar, el citado Convenio hispano-griego de 6 marzo 1919 estaba plena y perfectamente vigente para España en la fecha del litigio en cuestión. Es claro que la falta de aplicación de una norma jurídica vigente en Derecho español no supone la derogación de la misma y la no aplicación de la misma. Los tribunales están obligados a resolver el caso suscitado con arreglo al sistema legal de fuentes establecido, esto es, con arreglo a las normas jurídicas españolas que se encuentran en vigor en el momento de la controversia (art. 1.7 CC: "[l]os Jueces y Tribunales tienen el deber inexcusable de resolver en todo caso los asuntos de que conozcan, ateniéndose al sistema de fuentes establecido"). Del pleno vigor de este Convenio hispano griego de 1919 en Derecho español no cabe dudar ${ }^{4}$. Ya en 1992, F.F. Garau Sobrino había incluido dicho texto en su brillante y hoy ya clásico análisis del régimen jurídico de los efectos de las resoluciones extranjeras en España escrito en 1992, sin duda alguna sobre su vigencia. Sin embargo, dejaba constancia el citado autor de la escasa aplicación del Convenio en la práctica forense española, pues afirmaba, en relación con este Convenio, que "hasta el presente no nos consta su aplicación, por lo que su periodo de inactividad ya sobrepasa los setenta años"s. Ya varios años antes, en

\footnotetext{
${ }^{4}$ Este Convenio internacional estaba plenamente vigente para España en la en la fecha en la que se inicia el litigio ante los tribunales españoles (2009) y era también plenamente aplicable. Así lo acredita la doctrina española especializada en Derecho internacional privado (A. Borrás Rodríguez, N. Bouza Vidal, F.J. Garcimartín Alférez, M. Virgós Soriano, Legislación básica de Derecho internacional privado, Ed. Tecnos, Madrid, 23ª ed., 2014, pp. 1084-1089; A.-L. CAlvo CARAvaCA / J. Carrascosa González, Derecho internacional privado, vol. I, $16^{\text {a }}$ edición, Ed. Comares, Granada, 2016, pp. 753-762; F.F. Garau Sobrino, Lecciones de Derecho procesal civil internacional, 2a ed., Palma, Universitat de les Illes Balears, 2008, p. 143 y 202; F.F. Garau Sobrino, Los efectos de las resoluciones extranjeras en España, Madrid, Tecnos, 1992, pp. 82-83; A. Remiro Brotóns, Ejecución de sentencias extranjeras en España, Madrid, Tecnos, 1974, pp. 59-60. El hecho de que tras el 17 agosto 2015 y debido a la plena aplicación a partir de dicho día del Reglamento (UE) 650/2012 del Parlamento Europeo y del Consejo de 4 de julio de 2012 relativo a la competencia, la ley aplicable, el reconocimiento y la ejecución de las resoluciones, a la aceptación y la ejecución de los documentos públicos en materia de sucesiones mortis causa y a la creación de un certificado sucesorio europeo (DOUE L 201 de 27 julio 2012), resulte que el Convenio hispano-griego de 1919 no sea ya aplicable por los tribunales españoles, no empece la vigencia de dicho Convenio bilateral. Es, todavía en la actualidad, Derecho vigente en España aunque sea "Derecho no aplicable", desplazado por y en beneficio del citado Reglamento Sucesorio Europeo. Vid. en este sentido, el art. 75.2 del Reglamento 650/2012 citado, así como sus arts. 83 y 84 para las cuestiones de tipo transitorio. Debe tenerse presente que, a la fecha de interposición de la demanda que dio lugar a la SAP Islas Baleares de 4 mayo 2016, dicho Reglamento europeo no se había publicado oficialmente en el DOUE y, naturalmente, no estaba en vigor y que con arreglo al art. 44 LEC, "[p]ara que los tribunales civiles tengan competencia en cada caso se requiere que el conocimiento del pleito les esté atribuido por normas con rango de ley y anteriores a la incoación de las actuaciones de que se trate".

5 F.F. Garau Sobrino, Los efectos de las resoluciones extranjeras en España, Madrid, Tecnos, 1992, p. 83, nota [189],
} 
su espléndida monografía sobre la ejecución de las sentencias extranjeras en España, también A. Remiro BROTóNS se lamentaba de la falta de aplicación de este Convenio y de las escasas oportunidades que iba a tener de ser aplicado por los tribunales de Justicia ${ }^{6}$. La vida da muchas sorpresas y una de ellas es que no conviene desafiar al destino y descartar una concreta normativa legal del debate jurídico cuando dicha normativa está vigente. Siempre puede aparecer un juez o una parte que invoque una norma jurídica en vigor que es la que, a la postre, resolverá el caso. Así fueron las cosas en esta sentencia dictada por la Audiencia Provincial de las Islas Baleares el 4 mayo 2016. Es cierto que los jueces tienen la obligación de conocer el sistema de fuentes establecido en el Derecho español y las mismas normas jurídicas vigentes que se insertan en dicho sistema (art. 1.7 CC: jura novit curia). Tales normas jurídicas no deben ser probadas por las partes en el proceso judicial. Ahora bien, si los jueces no recuerdan las normas vigentes aplicables, las han olvidado, las han pasado por alto, creen que no están vigentes o nunca supieron de su existencia, nada impide que una parte, diligente, bien informada, aplicada y observadora, haga notar al tribunal cuáles son las normas legales en vigor aplicables para resolver un caso litigioso. Así sucedió en este supuesto. El sistema jurídico español es un sistema objetivo. Está compuesto por las normas jurídicas españolas vigentes y aplicables. No son los tribunales ni tampoco las partes las que deciden si una norma existe y/o está vigente y resulta aplicable. Suena muy kelseniano, pero es cierto: las normas jurídicas son las que son y ello no es disponible ni discutible, guste más o guste menos a tribunales y litigantes. Con arreglo al principio de perpetuatio jurisdicionis (art. 44 LEC) los tribunales españoles debían determinar su competencia internacional con arreglo a las normas jurídicas españolas en vigor en el momento de iniciarse el pleito y tales normas se recogían en el citado Convenio hispano-griego de 6 marzo 1919, vigente y aplicable en el momento de ejercicio de la acción. El art. 22 LOPJ no era aplicable a la cuestión y tampoco lo era el Reglamento 659/2012, instrumento legal no en vigor en dicho momento.

Es curioso también hacer notar que este Convenio hispano-griego no se encuentra recogido en algunas recopilaciones jurídicas de Derecho internacional privado disponibles en el mercado editorial. Así, por ejemplo, en la excelente colección de normas dirigida por S. Álvarez González, C. Esplugues Mota, P. Rodriguez Mateos, y S. Sanchez Lorenzo, este Convenio no aparece? ${ }^{7}$ Tampoco consta en la magnífica recopilación de textos legales de la que son autores M. CASADO Abarquero, J.L. Iriarte ÁnGEL, y A. MuÑoz FERNÁNDEZ ${ }^{8}$. El rizo puede rizarse: este Convenio hispano griego de 1919 no se recogía en la edición vigésima de la extraordinaria y pionera recopilación de textos legales de Derecho internacional privado preparada por A. Borrás Rodríguez, N. Bouza Vidal, Francisco J. Garcimartín Alférez y M. Virgós Soriano y publicada por la editorial Tecnos en el año 2010'. Sin embargo, el Convenio en cuestión aparece incluido entre los materiales legislativos de dicha recopilación a partir de su edición número 22, que vio la luz en 2012, esto es, cuando ya el litigio en cuestión se encontraba en su segunda instancia y el Convenio hispano-griego había sido ya alegado por la parte recurrente en apelación. También fuera de los estrados, algo sucedió, es evidente, en el camino al Cielo en torno al año 2010, año en el que se resolvió el recurso de apelación contra la desestimación de la declinatoria internacional.

12. En segundo lugar, la sabida, aunque no siempre bien observada primacía de la aplicación de las normas jurídicas de génesis internacional sobre las normas de producción interna, imponía la apli-

con cita textual de la obra de A. Remiro Brotóns, Ejecución de sentencias extranjeras en España, Madrid, Tecnos, 1974, pp. 59-60. Vid. también F.F. GARAu Sobrino, Lecciones de Derecho procesal civil internacional, $1^{\mathrm{a}}$ ed., Palma, Universitat de les Illes Balears, 2003, p. 143

6 A. Remiro Brotóns, Ejecución de sentencias extranjeras en España, Madrid, Tecnos, 1974, p. 60: "Ignoro la razón de ser del Tratado hispano griego. ¿Quién no asegura que por los años veinte las migraciones de una península a la otra era tan abundantes que la necesidad de este Tratado se hacía imperiosa? Será cosa de ilustrarse. Pero muy posiblemente su negociación, como tantas otras veces, debió ser producto de un azar o de la inquietud pactista de un diplomático meritorio. El caso es que ahí está... (...) puede afirmarse que sus negociadores, al convenirlo, estaban mirando decididamente hacia el futuro".

7 Vid. S. Álvarez González, C. Esplugues Mota, P. Rodriguez Mateos, S. Sanchez Lorenzo, Legislación de Derecho Internacional Privado, $19^{\mathrm{a}}$ edición, Comares, Granada, 2016.

8 M. Casado Abarquero, J.L. Iriarte Ángel, A. Muñoz Fernández, Derecho Internacional Privado, 14a ed., Aranzadi, Pamplona, 2016.

9 Vid. la edición más reciente: A. Borrás Rodríguez, N. Bouza Vidal, Francisco J. Garcimartín Alférez, M. Virgós SoRIANO, Legislación básica de Derecho Internacional privado, 16 a ed., Tecnos, Madrid, 2016. El Convenio aparece ya en la p. 1046 de esta edición (2016). El Convenio puede verse en la p. 1125 de la 22 ${ }^{\mathrm{a}}$ edición correspondiente al año 2012. 
cación preferente del Convenio hispano-griego y la no aplicación del art. 22.3 LOPJ a la cuestión de la competencia internacional de los tribunales españoles.

En defecto de instrumento legal europeo que resulte aplicable, los tribunales y autoridades españolas aplicarán las normas jurídicas españolas de competencia judicial internacional. Tales normas se contienen en los Convenios internacionales vigentes para España (art. 96.I CE, art. 1.5 CC, art. 21 LOPJ), normas que prevalecen sobre las normas españolas de producción interna que regulan la competencia judicial internacional. Así lo subraya la SAP Islas Baleares 4 mayo 2016: "La jurisdicción de los tribunales se rige, en primer lugar, por lo dispuesto en los tratados internacionales. Las normas de fuente internacional priman sobre las de producción interna (arts. 96.1 de la Constitución, art. 21 de la Ley Orgánica del Poder Judicial y 36.1 de la Ley de Enjuiciamiento Civil)". Ello significa que si en relación con un caso concreto es aplicable un Convenio internacional en vigor para España y que regula la competencia internacional de los tribunales españoles, las normas jurídicas españolas de producción interna resultan inaplicables al caso. En consecuencia, el art. 22 LOPJ no resultaba aplicable para determinar la competencia internacional de los tribunales españoles en el caso en cuestión, ya que dicho precepto presenta un carácter meramente subsidiario. Este art. 22 LOPJ sólo puede aplicarse en defecto de normativa europea o de Convenio internacional vigente para España y aplicable al supuesto. Así lo confirma, específicamente, el art. 21. 1 LOPJ, cuyo texto actualmente vigente indica que "[l]os Tribunales civiles españoles conocerán de las pretensiones que se susciten en territorio español con arreglo a lo establecido en los tratados y Convenios internacionales en los que España sea parte, en las normas de la Unión Europea y en las leyes españolas". Por tanto, los criterios jurídicos para decidir si los tribunales españoles eran competentes para resolver el caso debían extraerse del Convenio hispano-griego de 1919 y no del art. 22.3 LOPJ. El sistema de competencia judicial internacional recogido en el art. 22 LOPJ para los litigios en el orden civil queda totalmente desactivado en presencia del Convenio hispano-griego de 1919, que prevalece sobre dicha normativa legal de producción interna.

13. La decisión que adoptó el Juzgado de primera instancia en torno a la competencia internacional de los tribunales españoles en el caso en cuestión era, pues, errónea. El Juzgado no aplicó la normativa legal en vigor y de aplicación preferente (= el Convenio hispano-griego de 1919) sino que tuvo presente el art. 22 LOPJ, precepto inaplicable al caso. Es por ello que todo el debate suscitado en torno al lugar en el que el causante tuvo su último domicilio era estéril y totalmente irrelevante. En efecto, el juzgado de primera instancia, en aplicación, incorrecta, del art. 22 LOPJ, estimó que el foro que atribuía competencia internacional a los tribunales españoles era uno de los recogidos en el párrafo tercero de dicha norma, y en concreto, el foro del "último domicilio del causante en territorio español". Debate, en efecto, inútil, porque esta circunstancia (= el último domicilio del causante) no se emplea como foro de competencia judicial internacional en el Convenio hispano-griego de 1919.

14. No seleccionar correctamente la norma jurídica aplicable no sólo constituye un error de envergadura en el razonamiento jurídico, sino que lleva a esfuerzos vanos como los del tristemente célebre Sísifo. En realidad es así, ya que Sísifo no quería morir y no moría, pero era obligado a trabajar de modo inútil, pues la enorme piedra siempre rodaba ladera abajo. De la misma manera, el jurista que razona con normas no aplicables e ignora normas vigentes y aplicables está también condenado a argumentar de modo inútil. Es, por tanto, un castigo tan irónico como el de Sísifo, pues su trabajo argumentativo es improductivo, yermo e infecundo y tiene que volver a comenzar y hasta que no admite que debe argumentar con arreglo a otras normas jurídicas, su castigo no cesa.

\section{Competencia judicial internacional y litigios sucesorios en el Convenio hispano-griego de 1919}

\section{A) Foros de competencia judicial internacional recogidos en el Convenio hispano-griego de 6 marzo 1919}

\section{a) Aspectos generales}

15. El Convenio hispano-griego de 6 marzo 1919 regula tanto la competencia internacional de los tribunales griegos como de los tribunales españoles (arts. XIII y XIV), así como la Ley aplicable a 
las sucesiones de los ciudadanos griegos y españoles (arts. XIII y XIV) y la ejecución en España de las sentencias griegas dictadas en aplicación del citado Convenio y viceversa (art. XV).

16. El Convenio hispano-griego de 1919 regula la sucesión mortis causa de los ciudadanos españoles y griegos fallecidos en Grecia y en España, respectivamente. Ése es el marco jurídico en el que debían buscarse los foros de competencia judicial internacional que permitían a los tribunales griegos y españoles declararse competentes para conocer de litigios sucesorios suscitados por tales ciudadanos. Como ha indicado la doctrina especializada, el Convenio hispano-griego de 6 marzo 1919 regula todo tipo de sucesión de todo tipo de bienes, se encuentren en el país en el que se encuentren. La rúbrica del Convenio hispano-griego así lo demuestra, pues el texto se refiere expresamente a "las sucesiones de los españoles $y$ de los griegos fallecidos en Grecia y en España, respectivamente" sin excluir ningún tipo de sucesión, y ningún tipo de bien, mueble o inmueble, sea cual fuere el país donde se encuentren tales bienes ${ }^{10}$.

17. En consecuencia, si las normas del citado Convenio no atribuyen competencia judicial internacional a los tribunales españoles ello significa que el legislador español no ha querido atribuir dicha competencia a tales tribunales. Por dicha razón, en tal caso, no puede acudirse, bajo ninguna circunstancia, a las normas de competencia judicial internacional recogidas en la LOPJ. Ello supondría una improcedente mezcla de normativas y fuentes jurídicas que contraviene la intención del legislador español de otorgar primacía aplicativa, en todo caso, a las normas contenidas en los Convenios internacionales sobre las normas contenidas en las normas españolas de producción interna (art. 21.1 LOPJ).

18. Por otra parte, si así se hiciera, esto es, si se aplicaran normas de competencia judicial internacional recogidas en la LOPJ a casos regulados por un Convenio internacional, se produciría una flagrante vulneración del Convenio internacional citado al permitir que los tribunales españoles fallaran en relación con un caso cuyo conocimiento les está prohibido por dicho texto legal. Debe recordarse que la inaplicación de un Convenio internacional en vigor para España comporta responsabilidad internacional del Estado español y que, por ello, España podría ser demandada ante el Tribunal Internacional de Justicia con sede en La Haya. Un caso similar se ha producido recientemente entre Suiza y Bélgica al acusar este país a Suiza de no aplicar un Convenio internacional (Convenio de Lugano de 16 septiembre 1988) en vigor para ambos Estados (demanda de 22 diciembre 2009, TIJ Press Release 2009/36 de 22 diciembre 2009) ${ }^{11}$.

\section{b) Competencia judicial internacional y sucesión mortis causa en relación con los bienes muebles: foro de la última nacionalidad del causante}

19. En cuanto a la competencia internacional de los tribunales en relación con los litigios sucesorios que afectan a la sucesión de los bienes muebles de los nacionales griegos fallecidos fuera de Grecia, el art. XIV de dicho Convenio indica que deberán decidirse exclusivamente ante los tribunales griegos. El texto del art. XIV del referido Convenio dice así: "La sucesión de los bienes muebles, así como el conocimiento de toda demanda o contestación relativa a ellos, se regirá por los Tribunales o Autoridades competentes del Estado a que pertenezca el difunto y conforme a las leyes de ese Estado". Se trata éste de un foro de competencia judicial internacional imperativo y exclusivo. Esta afirmación se demuestra mediante dos argumentos:

$\left.1^{\circ}\right)$ Argumento literal. La misma letra del precepto ordena al tribunal griego, con toda claridad, conocer del litigio sucesorio relativo a los bienes muebles de causante griego, lo que impide

10 F.F. Garau Sobrino, Los efectos de las resoluciones extranjeras en España, Madrid, Tecnos, 1992, pp. 82-83, nota [188]: "[d]el contexto del Tratado, parece que en ambos casos deberá referirse a los dos tipos de bienes (muebles e inmuebles), ya que los preceptos anteriores regulan la competencia judicial internacional referida a la sucesión de los bienes inmuebles (art. XIII) y muebles (art. XIV)".

11 A.-L. Calvo Caravaca / J. Carrascosa González, Derecho internacional privado, vol. I, 16 a edición, Ed.Comares, Granada, 2016, pp. 12-13. 
que pueda entrar otro tribunal de cualquier otro Estado en el conocimiento del litigio. Igualmente, con arreglo al precepto, los tribunales españoles deben conocer del litigio sucesorio relativo a los bienes muebles de causantes de nacionalidad española, lo que impide que un tribunal de cualquier otro Estado, incluida Grecia, entre en el conocimiento del litigio.

$2^{\circ}$ ) Argumento teleológico. También se desprende de la finalidad del precepto. En efecto, con ello se trata de evitar "pleitos internacionales paralelos", a desarrollar ante tribunales de diversos países, por elementales razones de economía procesal. En consecuencia, en el caso de sucesión de bienes muebles de los nacionales griegos fallecidos en España son exclusivamente competentes los tribunales griegos y, por lo tanto, los tribunales españoles carecen de competencia internacional para conocer de dichos litigios. En consecuencia, si se trata de un pleito relativo a la sucesión mortis causa de los bienes muebles de un ciudadano griego, los tribunales españoles deben declararse incompetentes de oficio para no vulnerar las reglas de competencia recogidas en el citado Convenio internacional.

20. La Audiencia provincial de las Islas Baleares realizó un potente trabajo argumentativo para concretar cuál era la nacionalidad del causante en el momento de su fallecimiento. Concluyó, y en esto no se hará mayor hincapié en la presente nota, que el causante ostentaba únicamente la nacionalidad griega y no la española al momento de su fallecimiento. El causante había perdido su nacionalidad española el año 2003 con arreglo al art. $24 \mathrm{CC}$ en su redacción vigente al tiempo de los hechos ${ }^{12}$. También consideró el juzgador insular que el causante tenía en el momento de su fallecimiento su residencia habitual en Grecia. En Grecia tuvo su último centro social y personal de vida y sus estancias en España fueron, desde 1999, puramente vacacionales, y en inmuebles que no eran de su propiedad. En consecuencia, la Audiencia Provincial de las Islas Baleares estimó que: (a) Los tribunales españoles no resultaban internacionalmente competentes para conocer del litigio sucesorio en cuestión en lo relativo a los bienes muebles; (b) Todos los litigios sucesorios relativos a la sucesión mobiliaria mortis causa del causante debían resolverse ante los tribunales griegos y con arreglo al Derecho sucesorio griego (art. XIV del Convenio hispano-griego de 6 marzo 1919).

\section{c) Competencia judicial internacional y sucesión mortis causa en relación con los bienes inmuebles: foro del lugar de situación de los bienes inmuebles}

21. En cuanto a la competencia internacional de los tribunales en relación con los litigios sucesorios que afectan a la sucesión de los bienes inmuebles de los nacionales griegos fallecidos fuera de Grecia, el art. XIII de dicho Convenio indica que tales los litigios sucesorios decidirse ante y por los tribunales del Estado de situación de los bienes inmuebles en cuestión y conforme a las Leyes de dicho país ("La sucesión de los bienes inmuebles, así como el conocimiento de toda demanda o contestación, convenientes a las sucesiones de los bienes inmuebles, se regirán por los Tribunales u otras autoridades competentes del país dentro del cual están situados los inmuebles y conforme a sus leyes"). Se trata, nuevamente, de un foro de competencia judicial internacional imperativo y exclusivo, por las mismas razones antes subrayadas.

22. En consecuencia, y siempre en el marco legal constituido por el Convenio hispano-griego de 1919, en el caso de sucesión de bienes inmuebles de los nacionales griegos fallecidos en España son exclusivamente competentes los tribunales del país de situación de los inmuebles y, por tanto, si tales bienes no se hallan en España, los tribunales españoles deben declararse incompetentes de oficio para no vulnerar las reglas de competencia recogidas en el citado Convenio internacional. Es irrelevante que los inmuebles se encuentren en Grecia o en otro país: si los inmuebles no se hallan en España sino en otro país, el Convenio internacional citado prohíbe taxativamente a los tribunales españoles el conocimiento de los litigios sucesorios relativos a dichos inmuebles, pues no les atribuye un foro de competencia judi-

12 J. Carrascosa González, Derecho español de la nacionalidad (Estudio práctico), Granada, Ed. Comares, 2011, pp. 208-224. 
cial para conocer del litigio. Y sin foro de competencia internacional aplicable, los tribunales españoles no pueden entrar en el conocimiento del litigio. En relación con la sucesión mortis causa de los bienes inmuebles del causante, la cuestión esencial radicaba en concretar el lugar de situación de los bienes inmuebles del causante en el momento de su fallecimiento. Su domicilio y nacionalidad, resultaban, a estos efectos, irrelevantes. Visto que, en el caso controvertido, los inmuebles incluidos en la herencia se hallaban localizados en Grecia y no en España, país donde dicho sujeto carecía de propiedad inmobiliaria alguna, la conclusión es clara: los tribunales españoles también carecían de competencia internacional para decidir el litigio sucesorio que afectaba a tales bienes inmuebles ya sí lo declaró la sentencia dictada por la Audiencia Provincial de las Islas Baleares 4 mayo 2016.

\section{B) Declaración, de oficio, de incompetencia de los tribunales españoles}

23. Los tribunales españoles no pueden declararse competentes en relación con un litigio respecto del que carecen de foros de competencia judicial internacional según la normativa aplicable, que es, en el presente supuesto, el Convenio hispano-griego de 6 marzo 1919.

\section{a) Principio general: no hay proceso sin competencia internacional}

24. Sin competencia judicial internacional, las autoridades y tribunales españoles no pueden entrar a conocer de un litigio derivado de una situación privada internacional. En efecto, los tribunales españoles sólo pueden declararse competentes en los casos previstos por la Ley. Así lo señalan diversos preceptos del ordenamiento jurídico español:

En primer lugar, la solución está ya implícita en el art. 117.3 de la Constitución española de 27 diciembre 1978 bien claro señala que "[e]l ejercicio de la potestad jurisdiccional en todo tipo de procesos, juzgando y haciendo ejecutar lo juzgado, corresponde exclusivamente a los Juzgados y Tribunales determinados por las leyes, según las normas de competencia y procedimiento que las mismas establezcan". La competencia judicial internacional debe ejercitarse con pleno respeto a los foros recogidos en el sistema jurídico.

En segundo lugar, diversas normas de la LOPJ enfatizan la misma idea, la concretan y la delimitan. Así, el art. 4 LOPJ precisa que "[l] a jurisdicción se extiende a todas las personas, a todas las materias y a todo el territorio español, en la forma establecida en la Constitución y en las Leyes". El art. 9.1 LOPJ establece que "[l]os juzgados y tribunales ejercerán su jurisdicción exclusivamente en aquellos casos en que les venga atribuida por ésta u otra Ley" y el art. 21.1 LOPJ, antes citado, dispone que "[l] os Juzgados y Tribunales españoles conocerán de los juicios que se susciten en territorio español entre españoles, entre extranjeros y entre españoles y extranjeros con arreglo a lo establecido en la presente Ley y en los tratados y Convenios internacionales en los que España sea parte".

En tercer lugar, a nivel de ley ordinaria, el art. 36.1 LEC 1/2000 indica que "[l]a extensión y límites de la jurisdicción de los tribunales civiles españoles se determinará por lo dispuesto en la Ley Orgánica del Poder Judicial y en los tratados y Convenios internacionales en los que España sea parte" $\mathrm{y}$ el art. 44 LEC advierte que "[p]ara que los tribunales civiles tengan competencia en cada caso se requiere que el conocimiento del pleito les esté atribuido por normas con rango de ley y anteriores a la incoación de las actuaciones de que se trate".

25. De los anteriores preceptos legales se derivan ciertas consecuencias jurídicas de extraordinaria envergadura para la solución correcta del litigio examinado y fallado por la SAP Islas Baleares 4 mayo 2016:

$\left.1^{\circ}\right)$ Los tribunales españoles deben, en todo caso, controlar de oficio su competencia internacional. Esta afirmación debe ser entendida en el sentido de que los tribunales españoles debe conocer, únicamente, de los litigios respecto de los cuales tienen atribuida la competencia judicial internacional en virtud de las normas legales vigentes en España. A tal efecto, los tribunales no dependen de las alegaciones y/o de las actuaciones de las partes (art. 21.1 LOPJ). 
$2^{\circ}$ ) Si el tribunal español advierte que carece de un foro de competencia judicial internacional, se declarará, en cualquier momento del procedimiento, incompetente. Los tribunales españoles sólo pueden conocer de un litigio internacional si disponen de un foro de competencia internacional al efecto. Lo declara muy bien la SAP Islas Baleares 4 mayo 2016: "El artículo 38 LEC dispone que la falta de competencia internacional se apreciará de oficio. La falta de jurisdicción determina la nulidad de pleno derecho de las actuaciones procesales (art. $225.1^{\circ}$ de la Ley de Enjuiciamiento Civil y 238.1 de la Ley Orgánica del Poder Judicial)". El hecho de que, en el caso de examen, el juzgador de primera instancia no haya tenido en cuenta el Convenio aplicable no impide que lo tenga presente la Audiencia y que, al aplicarlo, pueda deducir que los tribunales carecen de competencia internacional y que deben, por consiguiente, declararse incompetentes ${ }^{13}$.

$3^{\circ}$ ) Por razones de economía procesal, el art. 404.2.1 ${ }^{\circ}$ LEC indica que el tribunal español ante el que se ha presentado la demanda debe examinar su competencia in limine litis, de modo que si advierte que los tribunales españoles carecen de competencia internacional, se dictará auto en cuya virtud inadmite dicha demanda y se sobreseerán los autos ${ }^{14}$.

$4^{\circ}$ ) Las normas de competencia judicial internacional españolas o europeas que resultan aplicables a un concreto litigio son las únicas normas que deciden si los tribunales españolas deben conocer de una determinada pretensión jurídica. Son las únicas normas que indican si el Estado español debe aceptar o renunciar a asumir la tutela judicial en un caso concreto ${ }^{15}$.

$\left.5^{\circ}\right)$ La competencia internacional constituye un presupuesto del proceso. Por ello, si los tribunales españoles conocen de un litigio respecto del cual carecen de competencia judicial internacional, el proceso resulta nulo de pleno derecho a tenor del art. 238 LOPJ. Así lo ha indicado la mejor jurisprudencia, de la que es ejemplo la SAP Barcelona 26 mayo 2005: " $L a$ falta de jurisdicción o de competencia del órgano judicial que conoce de un procedimiento constituye una causa de nulidad (art. 238 LOPJ)"16. En un sentido similar también se pronuncia el AAP Badajoz 4 noviembre 2003.

26. En suma, de las anteriores disposiciones legales, que arrancan todas ellas del citado art. 117 CE 1978, es posible deducir un principio general básico en la ordenación valorativa del sector de la competencia judicial internacional: en los litigios internacionales, no puede desarrollarse un proceso ante tribunales españoles sin que éstos tengan atribuida legalmente competencia internacional. Cualquier interpretación que suponga quiebra de este principio es inconstitucional y debe ser rechazada de plano.

27. Es preciso examinar, en este momento, los mecanismos jurídicos técnico-procesales previstos en el Derecho español para proceder a declarar la falta de competencia judicial internacional de los tribunales españoles. En efecto, el tribunal español ante el que se haya presentado una demanda puede declararse incompetente por falta de competencia judicial internacional, a través de dos mecanismos técnicos alternativos: la declinatoria internacional y la abstención de oficio.

\section{b) La declinatoria internacional}

28. La excepción declinatoria, recogida en el art. 39 LEC $1 / 2000$ sirve para evitar que los tribunales españoles conozcan de un concreto litigio pese a que dichos tribunales disponen de un foro de

13 SAP Islas Baleares 4 mayo 2016: "De ello se deriva que la falta de jurisdicción o competencia internacional puede ser apreciada de oficio, incluso después de haber sido desestimada la declinatoria formulada por la parte demandada, especialmente si la nueva revisión se produce atendiendo al contenido de una norma que tiene aplicación preferente y que no fue tenida en cuenta en el momento de ser analizada la cuestión por primera vez....".

14 Vid., en tal sentido, SAP Guipúzcoa 22 mayo 2014 (modificación de régimen de visitas de menor con residencia en Francia).

15 SAP Vizcaya 26 mayo 2011 (cesión de futbolista profesional a club extranjero), STC Sala 2a 28 febrero 2011 (competencia de la jurisdicción española y acción de filiación).

16 [Id Cendoj: 08019370152005100175]. 
competencia internacional previsto en el Derecho europeo o español que les permitiría conocer de tal litigio. El dictum del precepto confirma la anterior afirmación: "[e]l demandado podrá denunciar mediante declinatoria la falta de competencia internacional o la falta de jurisdicción por pertenecer el asunto a otro orden jurisdiccional o por haberse sometido a arbitraje o mediación la controversia". Esto es, los tribunales españoles han examinado su competencia internacional $\mathrm{y}$, al haber encontrado un foro de competencia a su favor, están en disposición de declararse competentes. Sin embargo, el legislador español entiende que, aunque los tribunales españoles disponen de tal foro de competencia internacional, el demandado puede hacer valer un pacto de sumisión a arbitraje, mediación o a tribunales extranjeros. El objetivo del demandado es evitar que conozcan del litigio los tribunales españoles y que, por el contrario, sean los árbitros, los mediadores o los tribunales extranjeros los que conozcan de un litigio que las partes habían sometido a tales árbitros, mediadores o tribunales extranjeros. El citado art. 39 LEC recoge con claridad esta idea. En efecto, el demandado puede denunciar mediante declinatoria la falta de competencia internacional o la falta de jurisdicción por pertenecer el asunto a otro orden jurisdiccional o por haberse sometido a arbitraje o mediación la controversia. Es decir, es el demandado el que debe hacer valer, en el proceso iniciado en España, que existe una cláusula válida de sumisión en cuya virtud el litigio se ha sometido la controversia a tribunales de otro Estado, o a arbitraje o mediación. Si concurre un foro de competencia internacional en las normas europeas o españolas aplicables al caso a favor del tribunal español que conoce del asunto, éste no puede, de oficio, dejar de conocer del litigio aunque exista una cláusula de sumisión en favor de tribunales de otro Estado o de un arbitraje. En tal supuesto, corresponde al demandado, y sólo al demandado, hacer valer tal cláusula de sumisión y solicitar la declaración de incompetencia internacional del tribunal. Si el demandado no lo hace, el tribunal continúa en el conocimiento del asunto porque dispone de un foro de competencia internacional que le obliga a ello. Cierto es que la declinatoria puede emplearse para "hacer ver" al tribunal su falta total de competencia judicial internacional, esto es, que no existe foro alguno de competencia judicial internacional a su favor. Sin embargo, el objetivo principal de la declinatoria radica en iluminar al tribunal español y comunicarle que el litigio se ha sometido previamente a tribunales extranjeros, árbitros o mediadores y que, precisamente por ello, aun cuando el tribunal español disponga de un foro de competencia judicial internacional, debe declararse incompetente y dejar que el litigio se desarrolle ante los tribunales extranjeros, árbitros o mediadores previamente elegidos por las partes.

\section{c) La abstención de oficio por falta de competencia internacional}

29. El art. 36.2 LEC, precepto de importancia basilar en el sistema español de Derecho internacional privado, dispone lo siguiente:

"2. Los tribunales civiles españoles se abstendrán de conocer de los asuntos que se les sometan cuando concurra en ellos alguna de las circunstancias siguientes:

1. ${ }^{a}$ Cuando se haya formulado demanda o solicitado ejecución respecto de sujetos o bienes que gocen de inmunidad de jurisdicción o de ejecución conforme a las normas del Derecho Internacional Público.

2. ${ }^{a}$ Cuando, en virtud de un tratado o Convenio internacional en el que España sea parte, el asunto se encuentre atribuido con carácter exclusivo a la jurisdicción de otro Estado.

3. ${ }^{a}$ Cuando no comparezca el demandado emplazado en debida forma, en los casos en que la competencia internacional de los tribunales españoles únicamente pudiera fundarse en la sumisión tácita de las partes".

30. Interesa exponer y profundizar en la causa de abstención judicial recogida en el art. 36.2.3 LEC. Este inciso indica que si los tribunales españoles carecen de un foro de competencia internacional en relación con un concreto asunto, deben verificar si el demandado se somete tácitamente a dicho tribunal. En el caso de que se someta de modo implícito, concurre el foro de competencia internacional denominado precisamente, "sumisión tácita del demandado". De ese modo, y en virtud del mismo, el tribunal español será competente en virtud, naturalmente, del foro de la sumisión tácita de las partes siempre y cuando las normas legales aplicables a la competencia judicial internacional de los tribunales 
españoles admitan la sumisión como foro de competencia judicial internacional (art. 22 bis LOPJ, art. 26 RB I-bis $)^{17}$.

Si los tribunales españoles carecen de un foro de competencia internacional y, además, el demandado no se ha sometido a los tribunales españoles, entonces éstos carecen de todo foro de competencia internacional. Por ello, en este caso, se declararán de oficio incompetentes (art. 36.2.3 ${ }^{\mathrm{a}}$ LEC) en cuanto adviertan que carecen de un foro de competencia internacional que les permita conocer del asunto (art. 38 LEC). Así lo indica con la mayor rotundidad y vehemencia la doctrina que se ha ocupado del particular ${ }^{18}$.

31. En el presente caso, como se ha indicado, la competencia judicial internacional de los tribunales españoles se debe regular, exclusivamente, por el Convenio hispano-griego de 6 marzo 1919.

Dicho texto no recoge ni admite la sumisión como foro de competencia judicial internacional. En consecuencia, los tribunales españoles no podían declararse internacionalmente competentes con arreglo a la sumisión de las partes en ningún caso.

El único foro de competencia judicial internacional con arreglo al cual los tribunales españoles habrían podido declararse competentes para conocer del pleito sucesorio relativo a los bienes muebles de la herencia era la nacionalidad española del causante. Como antes se ha indicado, el causante no ostentaba la nacionalidad española en el momento de su fallecimiento, sino única y exclusivamente la nacionalidad griega. Por consiguiente, los tribunales españoles carecían de competencia internacional en relación con la sucesión de los bienes muebles del testador. Es por ello que la Audiencia declaró de oficio su falta de competencia internacional en cualquier momento del procedimiento, es decir "tan pronto como sea advertida [por el tribunal] la falta de competencia internacional".

32. En tal sentido, debe recordarse que los tribunales españoles no pueden ignorar los casos en los que las normas españolas de competencia judicial internacional no les otorgan dicha competencia internacional. Estas normas españolas de competencia internacional "son de orden público y por tanto, de inexcusable cumplimiento"19. Con ello quiere decirse que los tribunales españoles deben aplicar de oficio las normas de competencia judicial internacional también en su sentido negativo, esto es, con el objetivo de evitar que los tribunales españoles conozcan de asuntos respecto de los cuales son internacionalmente incompetentes, lo cual resultaría contrario al principio de legalidad recogido en el misma Constitución española (art. 9.1 CE 1978), así como a los citados art. 4 LOPJ, art. 9 LOPJ, art. 21 LOPJ, art. 36.1 LEC, art. 38 LEC y art. 44 LEC.

33. Por tanto, la conclusión es clara. Cuando un litigio relativo a una situación privada internacional se presenta ante los tribunales españoles, éstos deberán declararse de oficio incompetentes en

17 La redacción actualmente vigente del artículo 22 bis LOPJ obedece a la Ley Orgánica 7/2015, de 21 de julio, por la que se modifica la Ley Orgánica 6/1985, de 1 de julio, del Poder Judicial (BOE núm. 174 de 22 de julio 2015). En su párrafo primero el precepto señala que "[e]n aquellas materias en que una norma expresamente lo permita, los Tribunales españoles serán competentes cuando las partes, con independencia de su domicilio, se hayan sometido expresa o tácitamente a ellos. No surtirán efectos los acuerdos que atribuyan la competencia a los Tribunales españoles ni las estipulaciones similares incluidas en un contrato si son contrarios a lo establecido en los artículos 22 quáter, 22 quinquies, 22 sexies y 22 septies, o si excluyen la competencia de los órganos judiciales españoles exclusivamente competentes conforme lo establecido en el artículo 22, en cuyo caso se estará a lo establecido en dichos preceptos".

18 Vid. A.-L. Calvo Caravaca / J. Carrascosa González, Derecho internacional privado, vol. I, 16a edición, Ed.Comares, Granada, 2016, pp. 335-342. También R. Arenas García, El control de oficio de la competencia judicial internacional, Madrid, Eurolex, 1996, pp. 300-301: "en ausencia de competencia no es posible producir una decisión sobre el fondo del asunto, con lo que el órgano jurisdiccional, exista o no alegación de parte, deberá abstenerse. En nuestro sistema autónomo esta conclusión puede extraerse de los arts. 117.3 de la Constitución, y 9.1 y 21 de la LOPJ, en los que se prohíbe a los órganos judiciales el ejercicio de la función jurisdiccional fuera de los supuestos en los que tengan atribuida competencia (...) Si el demandado impugna la competencia de los Tribunales españoles con anterioridad a contestar al fondo del asunto no cabrá deducir la sumisión tácita de éste, por lo que, pese a que la actuación del demandado presente vicios que impidan la eficacia de su solicitud de abstención, ésta no impedirá el ejercicio por el tribunal de su obligación de verificar de oficio la concurrencia de competencia judicial internacional, y proceder a la abstención en caso de que no concurra ningún criterio de competencia en nuestro sistema".

19 Vid. AAP Palma de Mallorca 9 octubre 2007 (contrato firmado en el extranjero, entre extranjeros y a ejecutar fuera de España) [Id Cendoj: 07040370032007200086]. 
caso de ausencia de foro de competencia judicial internacional en su favor. Es decir, si no concurre un foro de competencia judicial internacional de los recogidos en las Leyes procesales españolas en favor de los tribunales españoles, éstos, directamente, se declararán incompetentes y lo harán de oficio ${ }^{20}$. La jurisprudencia española es clara en este punto: sin competencia judicial internacional en favor de los tribunales españoles, éstos deben abstenerse de conocer del proceso en cuestión ${ }^{21}$.

20 Vid. el AAP Palma de Mallorca 9 octubre 2007 (contrato firmado en el extranjero, entre extranjeros y a ejecutar fuera de España), citado en la nota anterior.

21 Vid. STS 25 junio 2008 [Id Cendoj: 28079110012008100543]: "Resulta imprescindible, por lo tanto, dar respuesta a esta cuestión, cuyo carácter de orden público es notorio -lo que deja expedito su examen de oficio-, y verificar si los tribunales españoles tienen competencia para conocer de unas pretensiones que tienen por objeto la revocación de un testamento otorgado en el extranjero por otro posterior otorgado en España y la declaración de ineficacia de los actos jurídicos que son consecuencia del primero. Este control de la competencia judicial internacional ha de hacerse necesariamente a la vista de lo dispuesto en el artículo 22 de la Ley Orgánica del Poder Judicial, a falta de norma convencional o, en general, de norma de carácter supranacional que resulte aplicable, y, en concreto, a la vista de lo dispuesto en su apartado tercero, una vez que se ha comprobado que no concurren ninguno de los foros de competencia exclusiva que establece el apartado primero del mismo artículo, y después de que se han excluido los foros generales establecidos en su apartado segundo, ya que no hay pacto expreso de atribución de competencia en favor de los tribunales españoles ni sumisión tácita a éstos, y que falta la conexión del domicilio del demandado que sirve para atribuir la competencia a los tribunales españoles"; SAP Barcelona 3 julio 2014 [divorcio entre cónyuges ecuatorianos y alimentos], Id Cendoj: 08019370122014100494]: "Visto que la sentencia apelada no examina la competencia de los tribunales españoles, como procede hacer de oficio según el artículo 38 de la Ley de Enjuiciamiento Civil (LEC), ni la ley aplicable a los temas objeto del procedimiento..."; SAP Barcelona 15 julio 2014 [divorcio entre cónyuges marroquíes] Id Cendoj: 08019370122014100517: "Ninguna de las partes ha suscitado en la alzada las cuestiones sobre competencia judicial ni ley aplicable, que han sido debatidas en la primera instancia. No obstante han de ser examinadas al tratarse ambas de materias de orden público, puesto que la competencia ha de ser examinada de oficio (tal como establecen los artículos 21 de la LOPJ y 770.4 de la LEC) y, en cuanto a la ley aplicable ha de respetar el sistema de fuentes y las normas de conflicto establecidas en el Título Preliminar del Código Civil (artículos 9, 13 y 107 CC) y los tratados internacionales de aplicación"; SAP Barcelona 29 julio 2014 [visitas a menor española, madre española y padre de nacionalidad cubana con residencia en los EE.UU] Id Cendoj: 08019370122013100498: "La demandante y el demandado (también demandante en los autos acumulados) son de nacionalidad bangladesí y religión musulmana (...). Dado que la sentencia apelada ignora esos elementos internacionales y no examina la competencia de los tribunales españoles, como procede hacer de oficio según el artículo 38 de la Ley de Enjuiciamiento Civil (LEC ), ni la ley aplicable ...."; SAP Barcelona 9 mayo 2014 [divorcio entre cónyuge norteamericano y española e hijos comunes], Id Cendoj: 08019370122014100299: "Visto que la sentencia apelada no examina la competencia de los tribunales españoles, como procede hacer de oficio según el artículo 38 LEC, ni la determinación de la ley aplicable a los temas objeto del procedimiento, según el artículo 12.6 del Código Civil estatal (CC), debe señalarse que el padre tiene la nacionalidad de EE.UU. y la madre, española ..."; SAP Guipúzcoa 22 mayo 2014 [modificación de régimen de visitas de menor con residencia en Francia], Id Cendoj: 20069370022014100060 : “A la vista de los términos en los que ha quedado configurado el presente recurso se está en el caso de abordar en primer lugar la cuestión relativa a la falta de competencia internacional que se alega toda vez que en función de lo que se resuelva al respecto procederá o no entrar a valorar el fondo de la cuestión debatida, esto es la procedencia o no de la modificación de medidas planteada por los demandantes. (...) La parte demandada con carácter previo a pronunciarse sobre la petición principal denunció, mediante declinatoria , la falta de competencia internacional al amparo de lo dispuesto en el artículo 63.2 de la L.E.C. (....) Con fecha 10 de abril de 2013 el Juzgado de Primera Instancia ${ }^{\circ} 4$ de Irún dictó resolución en virtud de la cual rechazaba las alegaciones formuladas sobre falta de competencia internacional del Tribunal para conocer del asunto planteado en la demanda. - Recurrida en reposición dicha resolución y habiéndose adherido al mismo el Ministerio Fiscal ,el Juzgado de Primera Instancia encargado de la cuestión resolvió mediante auto de fecha 5 de junio de 2013 y declaró no haber lugar a estimar el recurso de reposición rechazando la cuestión de competencia formulada. - Con fecha 14 de enero de 2014 se dictó sentencia (...) No puede admitirse en este caso la sumisión tácita y tampoco estamos ante un supuesto de sumisión expresa, o presunta por actos inequívocos anteriores a la demanda. Además, la propia regulación española establece también el examen de oficio de la competencia a tenor del artículo 38 de la L.E.C., igual que la territorial, art 769.4 LEC Es más incluso en esta alzada, cabe la apreciación de la falta de jurisdicción o la incompetencia de los Tribunales españoles según el artículo 227 último párrafo L.E.C. El Juzgado a quo debió examinar su propia competencia internacional detenidamente y, a limine litis, debió no admitir a trámite la demanda en cuanto a la responsabilidad parental y régimen de relación con los abuelos no custodios"; SAP Baleares 18 diciembre 2009 [menor extranjero con residencia habitual en España]: Id Cendoj: 07040370042009100441: "También hemos de destacar como es la jurisdicción de un Tribunal el primer basamento de su pronunciamiento y por ende la primera circunstancia que ha de ser determinada; en este sentido el art. 9.1 de la Ley Orgánica del Poder Judicial dispone que los Juzgados y Tribunales ejercerán su jurisdicción exclusivamente en aquellos casos en que les venga atribuida por esta u otra Ley, y el art. 22 de la propia Ley establece las reglas que determinan la competencia de los Juzgados y Tribunales españoles, con carácter imperativo y no dispositivo, por lo que su observancia ha de ser apreciada de oficio por el Juzgador, sin que la autonomía de la voluntad de las partes pueda alterar su aplicación de no existir sumisión"; AAP Baleares 9 octubre 2007 [contrato firmado en el extranjero, entre extranjeros y a ejecutar fuera de España] [Id Cendoj: 07040370032007200086]: “... Consecuentemente, estamos ante obligaciones contraídas en el extranjero, por extranjeros y que han de cumplirse fuera de España, por persona que ni ahora ni el momento de interponerse la demanda residia en nuestra 
34. En cuanto al momento en el que el tribunal español debe declararse de oficio incompetente y abstenerse de conocer por falta de competencia judicial internacional de la jurisdicción española y por corresponder el conocimiento del asunto a los tribunales griegos, el art. 38 LEC indica que "[l]a abstención a que se refieren los dos artículos precedentes se acordará de oficio, con audiencia de las partes y del Ministerio Fiscal, tan pronto como sea advertida la falta de competencia internacional o la falta de jurisdicción por pertenecer el asunto a otro orden jurisdiccional'. De nuevo, la jurisprudencia española enfatiza que los tribunales españoles deben abstenerse de conocer de oficio del asunto en cualquier momento del procedimiento y deben declarar la falta de competencia judicial internacional de los tribunales españoles si no concurren foros de competencia judicial internacional en favor de la jurisdicción española ${ }^{22}$.

35. En el presente caso, el hecho de haber contestado a la demanda por parte de la parte demandada no suponía la existencia de una sumisión de ésta al tribunal español.

En primer lugar, ello es así porque el citado Convenio hispano-griego de 6 marzo 1919, no admite la sumisión como foro de competencia judicial internacional.

En segundo lugar, no existe sumisión alguna por parte del demandado, ya que éste interpuso la declinatoria en su momento y tiene derecho a llevar a cabo su defensa sobre el fondo sin que ello suponga una voluntad por su parte, de haberse sometido al tribunal. Así lo subraya la jurisprudencia ${ }^{23}$.

36. En virtud del tantas veces citado Convenio hispano-griego de 6 marzo 1919, los litigios sucesorios relativos a bienes muebles de causantes de nacionalidad griega deben resolverse, exclusivamente, ante los tribunales griegos y con arreglo a la Ley griega (= Ley nacional del causante) y los litigios relativos a la sucesión de los bienes inmuebles de los nacionales griegos fallecidos fuera de Grecia deberán decidirse por los tribunales del Estado de situación de los bienes inmuebles en cuestión y conforme a las Leyes del país de situación de los inmuebles. Por consiguiente, en el presente supuesto,

nación, por lo que de acuerdo con los preceptos legales anteriormente indicados hay que concluir que los Tribunales españoles no son competentes para conocer la cuestión litigiosa que se pretende someter a su consideración. Señalar, por último, que las normas de competencia son de orden público y por tanto, de inexcusable cumplimiento"; AAP Barcelona 11 julio 2008 [Id Cendoj: 08019370122008200235]: "La Juzgadora de 1 ${ }^{a}$ Instancia ha declarado la falta de competencia de los juzgados y tribunales españoles al no concurrir ninguna de las circunstancias antes referidas, lo que debe ser confirmado en esta alzada procedimental, con desestimación del argumento de la recurrente que alega que ha solicitado la nacionalidad española, por ser de aplicación el principio de la "perpetuatio iurisdiccionis", que obliga al Juez a analizar las circunstancias y dictar sentencia de acuerdo con la situación fáctica existente en el momento de iniciarse el pleito, esto es en el momento de la presentación de la demanda, de manera que deben en ese momento analizarse si concurren las circunstancias referidas en el art. 22,3 LOPJ, sin que cualquier modificación ulterior por parte de las partes, como puede ser la adquisición de la nacionalidad española que ha solicitado la Sra. María Teresa pueda determinar la admisión de la demanda como pretende en su recurso".

22 Vid. inter alia: SAP Murcia 31 enero 2013 [guarda y custodia de menor con residencia habitual en Bolivia], Id Cendoj: 30030370042013100053: “... Estima este Tribunal, que si bien es cierto que el Sr. Artemio no denunció dicha falta de competencia a través de la vía procesal prevista legalmente al respecto, ello no constituye óbice alguno para que el Juzgador pueda en cualquier momento del procedimiento apreciarla de oficio, tras la correspondiente audiencia de las partes y del Ministerio Fiscal, como, en efecto, sucedió en este caso en el acto del juicio. Téngase en cuenta que la competencia de los Tribunales Españoles constituye una cuestión de orden público supervisable de oficio por los Tribunales"; AAP Madrid 27 junio 2012 [Id Cendoj: 28079370212012200196]: “... hemos de concluir que los tribunales españoles solo pueden declararse competentes en los "casos previstos en la ley", de forma que cuando un litigio relativo a una situación privada internacional se presenta ante un tribunal español debe declararse de oficio dicho Juzgado o Tribunal como no competente cuando, como se dice en el Art. 36 de la LECv, "en virtud de un tratado o Convenio internacional en el que España sea parte, el asunto se encuentre atribuido con carácter exclusivo a la jurisdicción de otro Estado ....".

23 Vid. AAP Madrid 7 septiembre 2012 [Id Cendoj: 28079370132012100436]: “Tampoco puede decirse que existió dicha sumisión por el hecho de que la demandada compareciera en el procedimiento concursal para defender sus intereses en relación con la calificación de la cantidad que en este se reclama, porque, como bien dice la apelante, en dicho procedimiento, primaba como fuero legal el domicilio del concursado (arts. 10 y 11 de la Ley Concursal) a los efectos de resolver la referida controversia, de manera que a la demandada solo le cabia la posibilidad de comparecer en el mismo si quería defender sus intereses; pero dicha comparecencia no comporta acto alguno de sumisión expresa o tácita en este, porque aquel procedimiento era distinto de este en el que es la concursada la que ejercita unas acciones que no son materia de concurso. $3^{\circ}$ ) Tampoco comporta sumisión tacita el hecho de que la demandada contestara a la demanda después de oponer, aunque fuera extemporáneamente, o si se quiere mediante una inexistente excepción de falta de competencia por las razones expuestas por la citada Sentencia de la A.P. de Murcia de 5 de diciembre de 2.005". 
los tribunales españoles debían declararse de oficio incompetentes en cualquier momento del proceso, tan pronto como adviertan su falta de competencia judicial internacional (art. 9.1 LOPJ, arts. 36.1, 38 y 39 LEC). No era preciso esperar la apelación de las resoluciones dictadas en primera instancia para que el tribunal español que conociera del caso pueda declarar su falta de competencia internacional. Con ello se da cumplimiento a la normativa procesal española citada y se satisface el economía procesal, así como el principio de la buena administración de la justicia.

37. Por tanto, en el caso objeto de la SAP Islas Baleares 4 mayo 2016, el tribunal sentenciador tenía ante sí una tarea más sencilla que la que finalmente se impuso a sí mismo. Le bastaba con comprobar, y no era difícil, que, con arreglo al citado Convenio hispano-griego, los tribunales españoles carecían de competencia internacional. Con ello, y al margen de toda consideración sobre las alegaciones de las partes en relación con la competencia internacional, hubiera sido suficiente para proclamar la falta de competencia internacional de los tribunales españoles y no entrar en el fondo del asunto. Sin embargo, el tribunal balear complicó el razonamiento al afirmar que debía proceder la declaración de incompetencia de los tribunales españoles por la razón de que el Convenio hispano-griego recogía una "competencia de carácter exclusivo en los términos del artículo 36 de la Ley de Enjuiciamiento Civil". Es cierto que es muy posible que así sea, esto es, que el Convenio hispano griego recoja foros "exclusivos", en el sentido de que sólo los tribunales españoles pueden conocer de las sucesiones de los españoles y sólo los tribunales griegos pueden conocer de los litigios relativos a la sucesión mortis causa de nacionales griegos ${ }^{24}$. No obstante, esta apreciación era totalmente innecesaria.

38. El error argumentativo del tribunal arranca de la lectura que éste hace del art. 38 LEC. El sistema español de competencia judicial internacional establece que, en ciertos casos, el tribunal español debe declararse de oficio incompetente. Se trata de los casos contemplados en el art. 38 y 36.2 LEC: (a) Casos en los que concurre la llamada "inmunidad de jurisdicción" o "inmunidad de ejecución" de conformidad con la legislación española y las normas de Derecho Internacional Público; (b) Casos en los que un tratado o Convenio internacional en el que España sea parte, establece que el asunto se encuentra atribuido con carácter exclusivo a la jurisdicción de otro Estado; (c) Supuestos en los que no comparece el demandado emplazado en debida forma, en los casos en que la competencia internacional de los tribunales españoles únicamente pudiera fundarse en la sumisión tácita de las partes. Este último caso significa que si no concurre ningún foro de competencia internacional y el demandado no se somete a los tribunales españoles, si es que la sumisión resulta permitida en el caso en cuestión, los tribunales españoles éstos carecen de foro de competencia internacional y, precisamente por carecer del mismo, deben declararse incompetentes de oficio y no conocer del asunto litigioso. Ello al margen de toda declinatoria. Y esto era lo que sucedía en el caso objeto de la SAP Islas Baleares 4 mayo 2016, aunque la Audiencia Provincial no supo verlo. En efecto, en este caso, los tribunales españoles no tenían a su favor ningún foro de competencia judicial internacional y el demandado no se había sometido a los tribunales españoles. La abstención de oficio era obligatoria e inexcusable con arreglo al art. 36.2.3 LEC.

39. Los tribunales españoles pueden declararse incompetentes si el demandado ha interpuesto declinatoria y ésta ha sido estimada (= control de la competencia internacional "a instancia de parte"). Ahora bien, fuera de tal supuesto, los tribunales españoles no pueden conocer de litigios en relación con los cuales carecen de foro de competencia internacional. En los casos no cubiertos por el art. 36.2 LEC, esto es, en los casos en los que el tribunal español no está autorizado a declararse de oficio incompetente, ello sucede porque el tribunal dispone de un foro de competencia internacional recogido en la normativa legal español que le permite entrar a conocer del litigio. La misión de la declinatoria internacional es

${ }^{24}$ En este sentido, indica la SAP Islas Baleares 4 mayo 2016 que: "Del propio tenor literal del precepto se deriva la existencia de un fuero de carácter exclusivo, sin que se prevean fueros de carácter alternativo que permitan una elección, ni la sumisión a los tribunales de otro estado distinto del de la nacionalidad. No puede entenderse que la excepción que se establece en el apartado segundo contradiga esta consideración. Por otro lado, está prevista para un supuesto en el que no se puede incluir al demandante, que no tiene nacionalidad española, ni reside en España, ni se han cumplido los plazos establecidos". 
advertir al juez español de que, pese, precisamente, a que dispone de un foro de competencia internacional a su favor, no debe entrar a conocer del fondo del asunto porque existe otro tribunal de otro Estado que cuenta con un foro de competencia internacional a su favor que debe operar con preferencia al foro establecido en beneficio de la jurisdicción española. El clásico ejemplo es el del acuerdo de sumisión en favor de tribunales de otros Estados o de arbitraje privado internacional. Si las partes acordaron litigar ante tribunales turcos, por ejemplo, pero el contrato debe ejecutarse en España, los tribunales españoles disponen de un foro de competencia internacional para solventar el litigio (art. 22 quinquies a] LOPJ). Queda en manos del demandado activar la declinatoria internacional para evitar que los tribunales españoles conozcan del asunto y a tal efecto deberá basar su declinatoria en la existencia de un previo y válido acuerdo de sumisión a favor de los tribunales turcos. En conclusión, nunca el art. 36.2 LEC puede ser interpretado contrario sensu con el resultado de que los tribunales españoles puedan conocer en relación con litigios no atribuidos a la jurisdicción española por la normativa española que regula la competencia judicial internacional.

\section{Reflexiones finales}

40. Este caso resulta interesante para recordar y reivindicar, con el mayor énfasis, la función del sistema jurídico y la precisión del Derecho aplicable.

En primer lugar, el Derecho es un sistema de normas jurídicas objetivas. El Derecho no es un sistema moral ni un conjunto nebuloso de reglas o pautas sociales. Ello significa que sólo forman parte de dicho sistema las reglas, normas y principios producidos según las propias disposiciones de dicho sistema. Resolver un caso con arreglo a preceptos o reglas externos a ese sistema jurídico constituye una solución antijurídica. Por ello resulta altamente preocupante la actitud de ciertos tribunales que aplican la equidad o su propio saber y entender para resolver litigios que deben solventarse con arreglo a normas jurídicas. Del mismo modo, acudir, en los casos regidos por el Derecho español, a normativas ajenas a éste constituye también una solución antijurídica, equivocada y errónea, por muy razonable que pueda parecer la solución. Alarmante es, por ello, que, por ejemplo, algunos tribunales españoles apliquen ciertos principios recogidos por la Conferencia de la Haya de Derecho internacional privado para determinar el país del domicilio del menor, principios resultado de una reunión entre expertos de varios Estados celebrada en Washington en marzo de 2010 (número especial de la International Family Law: "Declaración sobre la reubicación familiar internacional") o los Principios de Derecho Europeo de Familia relativos a la responsabilidad parental elaborados por la Comisión Europea de Derecho de familia (UE) ${ }^{25}$. Si el caso concreto resulta cubierto por el ámbito de aplicación de un Convenio internacional vigente para España, éste debe aplicarse y no hay otra opción, que es lo que ocurría en este caso con el Convenio entre España y Grecia, celebrado el 6 marzo 1919, fijando reglas que se han de aplicar a las sucesiones de los españoles y de los griegos fallecidos en Grecia y en España, respectivamente ${ }^{26}$. No es relevante que el Convenio sea antiguo, o no consten datos de su previa aplicación por los tribunales españoles. Los tribunales y las partes no pueden decidir cuáles son las normas vigentes en Derecho español.

En segundo lugar, en el actual estado del Derecho internacional privado español, el operador jurídico debe examinar con el mayor esmero, si existe o no un Convenio internacional antes de recurrir a normas españolas de producción interna. Tales normas son subsidiarias, pues sólo pueden aplicarse en defecto de Convenio internacional aplicable. Lo que es incluso mejor, pues la calidad de las normas

25 Vid., en este sentido, ad ex.: SAP Barcelona 28 septiembre 2015 (fijación de residencia en Londres de madre e hija), SAP Tarragona 26 octubre 2015 (traslado del domicilio de menor), SAP Barcelona 25 noviembre 2015 (traslado a Austria del domicilio de los menores), SAP Tarragona 22 diciembre 2015 (traslado de domicilio del menor), SAP Barcelona 11 diciembre 2015, SAP Barcelona 17 noviembre 2015.

${ }^{26}$ El texto oficial de este Convenio puede verse en la Gaceta de Madrid núm. 338 de 3 diciembre 1920. Dicho texto original y oficial puede consultarse en: https://www.boe.es/datos/pdfs/BOE//1920/338/A00952-00955.pdf. Este Convenio es ya inaplicable para España y también para Grecia tras la entrada en vigor y plena aplicabilidad del Reglamento (UE) 650/2012 del Parlamento Europeo y del Consejo de 4 de julio de 2012 relativo a la competencia, la ley aplicable, el reconocimiento y la ejecución de las resoluciones, a la aceptación y la ejecución de los documentos públicos en materia de sucesiones mortis causa y a la creación de un certificado sucesorio europeo (DOUE L 201 de 27 julio 2012). 
europeas suele ser muy superior a la que presentan las normas españolas. Los desastrosos arts. 22 a 22 nonies LOPJ introducidos por la Ley Orgánica 7/2015, de 21 de julio, constituyen una buena prueba de normas de "calidad cero" que introducen confusión y dañan los derechos de los particulares. Por fortuna, tales normas se encuentran desplazadas por multitud de normas europeas que regulan la competencia judicial internacional de los tribunales españoles y que, por tanto, muchas de ellas presentan hoy día un ámbito aplicativo real meramente subsidiario.

41. Por otro lado, también parece oportuno recordar que no siempre el legislador español dispone de una pluma bien cortada cuando regula la competencia internacional de los tribunales españoles. Así, en la regulación de la declaración de falta de competencia judicial internacional, las normas recogidas en la LEC 1/2000 no son tan transparentes, claras y terminantes como sería deseable. La función del operador jurídico es, pues, arrojar luz sobre normas oscuras, con el máximo respeto y la más elevada realización de los principios y valores constitucionales. Este caso es adecuado para no olvidar que los tribunales españoles no pueden decidir sobre el fondo de un litigio si carecen de un foro de competencia internacional que les permita conocer del asunto, ya que en caso contrario, la solución es contraria al mismo principio constitucional de legalidad. 